\title{
Pregnancy After a Laparoscopic Sacrohysteropexy: a Case Report
}

\section{Schwangerschaft nach laparoskopischer Sacrohysteropexie: ein Fallbericht}

Authors

Affiliations
M. Albowitz ${ }^{1}$, V. Schyrba ${ }^{2}$, D. Bolla ${ }^{1}$, A. Schöning ${ }^{1}$, R. Hornung ${ }^{1}$

${ }^{1}$ Obstetrics and Gynaecology, St. Gallen Cantonal Hospital, St. Gallen, Switzerland

${ }^{2}$ Obstetrics and Gynaecology, Heiden General Hospital, Heiden, Switzerland

\section{Key words}

- sacrohysteropexy

- pelvic organ prolapse

- pregnancy

- delivery

Schlüsselwörter

- Sacrohysteropexie

- Prolaps

- Schwangerschaft

- Entbindung

\section{received 8.4 .2014 \\ revised 16.8.2014 \\ accepted 18.8 .2014}

Bibliography

DOI http://dx.doi.org/

10.1055/s-0034-1383032

Geburtsh Frauenheilk 2014; 74 :

947-949 @ Georg Thieme

Verlag KG Stuttgart · New York ·

ISSN 0016-5751

\section{Correspondence}

\section{Dr. med. Marius Albowitz}

St. Gallen Cantonal Hospital

Obstetrics and Gynaecology

Rorschacherstrasse 95

9007 St. Gallen

Switzerland

marius.albowitz@kssg.ch

\section{Abstract \\ $\nabla$}

Pelvic Organ Prolapse (POP) is a rare condition during pregnancy. If all conservative treatments fail, the surgical approach has proven to be in non-pregnant women a very good option due to high efficacy and a very low morbidity and mortality rate. We are reporting on the clinical results of a 33-year-old pregnant woman with a past history of laparoscopic sacrohysteropexy who delivered by caesarean section due to a foetal breech presentation. There are only a handful of cases reporting the outcome "pregnancy" after a laparoscopic sacrohysteropexy. Nevertheless, this appears to be a useful intervention for women with a POP unresponsive to conservative treatment and open family planning. Further studies with long-term follow-ups are required to confirm this.

\section{Introduction}

$\nabla$

Pelvic Organ Prolapse (POP) is a disorder which affects millions of women worldwide [1]. POP is a condition that can negatively impact on the quality of life for patients because this condition often coexists with pelvic floor disorders like urinary or faecal incontinence [2]. If conservative treatments have failed, the surgical procedure has proven to be a good way to cure this condition with a high efficacy rate and very low rates of both mortality and morbidity [3]. The usual treatment for a utero-vaginal prolapse is a hysterectomy followed by pelvic support repair [4-5]. In young women suffering from POP, who are at childbearing age, the type of surgical approach is currently unclear. Studies have proven that young women are at high risk of a POP recurrence after

\section{Zusammenfassung \\ $\nabla$}

Descensus genitalis (Pelvic Organ Prolapse; POP) ist ein seltenes Leiden in der Schwangerschaft. Wenn alle konservativen Therapien erfolglos sind, hat sich, aufgrund einer hohen therapeutischen Wirksamkeit und einer niedrigen Morbiditätsbzw. Mortalitätsrate, ein chirurgisches Vorgehen bei nicht graviden Frauen als eine gute therapeutische Option herausgestellt. Wir beschreiben den klinischen Verlauf einer 33-jährigen Patientin, die nach einer laparoskopischen Sakrohysteropexie schwanger wurde und, aufgrund fetaler Beckenendlage, per Kaiserschnitt entbunden wurde. Nur wenige Fallbeispiele beschreiben das Outcome „Schwangerschaft“" nach laparoskopischer Sakrohysteropexie. Trotzdem erscheint dies ein sinnvoller Eingriff bei konservativ-therapierefraktärem POP und nicht abgeschlossener Familienplanung zu sein. Weitergehende Studien mit Langzeit-Follow-up werden hierfür zur Überprüfung benötigt.

surgical treatment but so far no studies have evaluated the impact of surgical POP repair on subsequent pregnancies and types of delivery [6]. This article describes the case of a woman who had an unproblematic pregnancy and delivered without incident 13 months after a laparoscopic sacrohysteropexy. The concerning literature is reviewed and summarized.

\section{Case \\ $\nabla$}

A 33-year-old IV-gravida, III-para was referred to our hospital at $384 / 7$ weeks of gestation for an elective caesarean section due to foetal breech presentation and history of POP repair. Her obstetrical history consisted of two uneventful vaginal deliveries and a forceps extraction. Thirteen 
months prior to the present pregnancy, the patient was recommended by our urogynaecologist to undergo a laparoscopic sacrohysteropexy for a symptomatic stage III POP without stress urinary incontinence. The Pelvic Organ Prolapse Quantification (POP-Q) measurements were $\mathrm{Aa}+2, \mathrm{Ba}+3, \mathrm{C}+3,5, \mathrm{Ap}+2$, $\mathrm{Bp}+2,5, \mathrm{D}+1, \mathrm{GH} 3,5$, PB 2,5, and TVL 10. There was however a desire for an additional pregnancy. The patient decided for the surgical option because the conservative treatments, which consisted of pelvic floor strengthening exercises and the use of multiple different pessaries only led to a slight improvement of the symptoms.

Regarding the surgical process, the patient was administered a single shot of $2 \mathrm{~g}$ cefazolin one hour prior to the intervention. Under general anaesthesia, the patient was positioned in a modified dorsolithotomy position in order to access both vagina and rectum appropriately. A uterus manipulator (Valtchev) was inserted into the uterine cavity. After establishing an adequate pneumoperitoneum using a Veress needle, a laparoscope was inserted intraabdominally through the infraumbilical trocar sleeve. After that, three additional trocars were established: one in the midline suprabubically and two others on each side of the lower abdomen, lateral to the epigastric vessels. The peritoneal cavity was inspected and showed no pathological findings. An area as large as required for fixing the mesh was incised on the promontory with monopolar scissors, slightly dextrolateral to the midline. The peritoneal incision was extended along the rectosigmoid colon towards the deepest part of the cul-de-sac, opening the recto- and vesicovaginal space. Both the lateral and the caudal incisions were extended in order to form a proper mesh-compartment. A partially absorbable mesh (Ultrapro ${ }^{\circledR}$, Ethicon Inc, Somerville, USA) was inserted into this compartment. In order to suspend the uterus, the mesh was sutured onto the cervix with six non-absorbable polyester 2-0 sutures. The other end of the mesh was then stapled to the sacral promontory using $5-\mathrm{mm}$ helical fasteners (Pro Tack ${ }^{\mathrm{TM}}$, Covidien plc, Dublin, Ireland). The opened recto- and vesicovaginal spaces were reperitonealised, using a running suture. The surgery was unremarkable with minimal blood loss. The postoperative stay was uneventful. Postoperative POP-Q measurements were $\mathrm{Aa}-2$, $\mathrm{Ba}-2.5, \mathrm{C}-5.5, \mathrm{Ap}-2$, Bp -2, D -8, GH 3, PB 3, and TVL 10 indicating a stage 0-1 POP. The patient could be discharged from the hospital after 3 days with no physical complaints.

The subsequent pregnancy occurred three months after the laparoscopic intervention and before the appointed postoperative routine check-up could take place. The course of pregnancy was, apart from foetal breech presentation, uneventful. A healthy newborn was delivered by caesarean section at 38 weeks of gestation. The clinical follow-up which consisted of a physical and sonographical evaluation of the pelvic floor was scheduled three months after the caesarean section. It showed no POP recurrence with the same POP-Q measurements as the preoperative staging.

\section{Discussion}

$\nabla$

Due to demographic changes, women tend to have POP even in their fertile age. If untreated, POP may impair a pregnancy. There are severe complications within the ante-, peri- and postnatal period due to a POP. Severe antenatal complications include e.g. preterm labour, premature labour or miscarriage. Perinatal problems such as an increase in the number of cervical lacerations have been observed. Postnatal complications can be subfertility
Table 1 Published case reports of pregnancies after pelvic organ prolapse surgery repair.

\begin{tabular}{|c|c|c|}
\hline Authors & No. of patients & Follow-up for POP after delivery \\
\hline Albowitz et al. & 1 & No recurrence after 3 months \\
\hline Busby et al. & 1 & No recurrence after 12 months \\
\hline Hefni et al. & 1 & No recurrence after 24 months \\
\hline Lewis et al. & 1 & Recurrence after 24 months \\
\hline Zucchi et al. & 3 & Not reported \\
\hline
\end{tabular}

due to chronic cervicitis $[6,7]$. For this reason in the last couple of years, uterus preserving surgical techniques such as the laparoscopic sacrohysteropexy have been developed [8-10].

There are only a few reports on pregnancies following POP repair. These cases are summarized in $\square$ Table 1 . In all cases the mode of delivery was a caesarean section, which was performed without complications each time. Except for one case in which a POP recurrence was observed 24 months after delivery, the follow-up was uneventful [9,11-13].

Indication to treat a POP during a pregnancy is rare. This is because the growing uterus temporarily resolves a uterine prolapse. In addition to the ongoing mechanical restructuring of the uterus during a course of pregnancy, biochemical changes of the connective tissue structures strengthen the pelvic floor [6].

On the other hand, non-pregnant women who experienced failure of conservative treatments, are very likely to seek a rapid improvement of their quality of life choosing a surgical approach.

So far, there is no guideline for obstetrical management of women who have undergone a POP repair procedure. However, there is a tendency not to encourage vaginal delivery in these situations. This seems most likely due to the unclear impact on the reconstructive surgery outcome [9,11-13].

Lewis et al. reported a case in which the patients POP recurred two years after the pregnancy [11]. This was an important point for the authors to emphasize the need for further follow-up in similar cases. Barranger et al. reported a POP recurrence rate of $6.6 \%(n=2)$ in parous women after an abdominal sacrohysteropexy $(n=30)$ with a mean follow-up of 94 months. Given the limited data, it is difficult to evaluate whether the POP recurrence was due to the pregnancy itself or caused by other underlying factors. In addition, in this study three of the women became pregnant after an abdominal sacrohysteropexy. In all of these cases, the women underwent legal abortions [10]. However, to our knowledge, the reproductive performance after POP has not been investigated.

Our patient was free of discomfort and symptoms of POP recurrence three months post partum. Recent studies comparing the laparoscopic with the abdominal sacrohysteropexy showed no difference in recurrence rate. The success rate in anatomical restoration was $94.9 \%$ after 43 months of follow-up [4].

\section{Conclusion}

$\nabla$

A pregnancy after a laparoscopic sacrohysteropexy would appear to be possible without increased risk of recurrence of POP. Consequently, surgical treatment of pelvic organ prolapse, even if family planning is not completed, can be a beneficial and useful therapeutic option. Studies with long-term follow-up are needed to confirm this. 


\section{Conflict of Interest}

None.

\section{References}

1 Patel PD, Amrute KV, Badlani GH. Pelvic organ prolapse and stress urinary incontinence: a review of etiological factors. Indian J Urol 2007; 23: $135-141$

2 Hendrix SL, Clark A, Nygaard I et al. Pelvic organ prolapse in the Women's Health Initiative: gravity and gravidity. Am J Obstet Gynecol 2002; 186: 1160-1166

3 Naumann G, Kölbl $H$. Current developments and perspectives on the diagnosis and treatment of urinary incontinence and genital prolapse in women. Geburtsh Frauenheilk 2012; 72: 202-210

4 Khunda A, Vashisht A, Cutner A. New procedures for uterine prolapse. Best Pract Res Clin Obstet Gynaecol 2013; 27: 363-379

5 Graefe F, Marschke J, Dimpfl T et al. Vaginal vault suspension at hysterectomy for prolapse - myths and facts, anatomical requirements, fixation techniques, documentation and cost accounting. Geburtsh Frauenheilk 2012; 72: 1099-1106
6 Tsikouras P, Dafopoulos A, Vrachnis $N$ et al. Uterine prolapse in pregnancy: risk factors, complications and management. J Matern Fetal Neonatal Med 2014; 27: 297-302

7 Mohamed-Suphan N, Ng RK. Uterine prolapse complicating pregnancy and labor: a case report and literature review. Int Urogynecol J 2012; 23: $647-650$

8 Johnson JA, Tough S. Delayed child-bearing.J Obstet Gynaecol Can 2012; 34: 80-93

9 Zucchi A, Lazzeri M, Porena $M$ et al. Uterus preservation in pelvic organ prolapse surgery. Nat Rev Urol 2010; 7: 626-633

10 Barranger E, Fritel X, Pigne A. Abdominal sacrohysteropexy in young women with uterovaginal prolapse: Long-term follow-up. Am J Obstet Gynecol 2003; 189: 1245-1250

11 Lewis CM, Culligan P. Sacrohysteropexy followed by successful pregnancy and eventual reoperation for prolapse. Int Urogynecol J 2012; 23: 957-959

12 Busby G, Broome J. Successful pregnancy outcome following laparoscopic sacrohysteropexy for second degree uterine prolapse. Gynecol Surg 2010; 7: 271-273

13 Hefni M, El-Toukhy T. Sacrospinous cervico-colpopexy with follow-up 2 years after successful pregnancy. Eur J Obstet Gynecol Reprod Biol 2002; 103: 188-190 